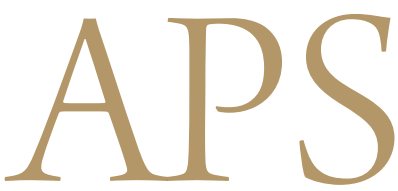

Archives of Plastic Surgery

\title{
A modified method for corner mouth lift in scar- prone patients
}

\author{
Kyung Hee Min ${ }^{1 *}$, Hyun Jic Lee ${ }^{2 *}$, Chang Ho Jeong ${ }^{1}$, Tae Kwang Jeong ${ }^{2}$ \\ ${ }^{1}$ Department of Plastic and Reconstructive Surgery, Nowon Eulji Medical Center, Eulji University School of Medicine, Seoul; ${ }^{2} H B$ Plastic \\ Clinic, Seoul, Korea
}

Corner mouth lift is in increasing demand among young patients in East Asia. Although various surgical methods exist for corner mouth lift, many patients are reluctant to undergo surgery due to fears of postsurgical scarring. We present a new technique aimed at reducing postoperative scarring. The technique involves triangular excision of the corner of the mouth and incision of the commissure with transposition of a lateral vermilion flap to lift the corner of the mouth. The muscle around the corner of the mouth is dissected to release tension. The corner mouth lift was successfully performed in all patients. It can be effectively used even in patients, such as young Asian women, who are susceptible to hypertrophic scars.

Keywords Aesthetics / Lip / Hypertrophic scar / Plastic surgery / Cosmetic surgery

Correspondence: Tae Kwang Jeong HB Plastic Clinic, 5F, Miso Bd, 13 Eonju-ro 174-gil, Gangnam-gu, Seoul 06017, Korea

Tel: $+82-1522-5515$

Fax: +82-2-546-6700

E-mail: 4748tkhr@daum.net

*The two authors contributed equally to this work.

Received: March 16, 2020 • Revised: July 14, 2020 • Accepted: July 22, 2020

pISSN: 2234-6163 • elSSN: 2234-6171 • https://doi.org/10.5999/aps.2020.00444• Arch Plast Surg 2020;47:622-625

\section{INTRODUCTION}

The appearance of the corner of the mouth plays an important role in other people's first impressions of a person's face. A downturned corner of the mouth is a typical characteristic of aging [1], but may also be congenital. It is regarded as a negative expression, indicating emotions such as sadness and depression. Consequently, most people prefer and desire upturned corners of their mouth, as they are regarded as conveying favorable expressions. Surgical lifting of the corners of the mouth may contribute to creating a smiling face and youthful appearance [2]. In the past, surgery of the corners of the mouth was mostly performed to improve the features of aging faces. However, in recent years, young women have increasingly often chosen these treatments for esthetic purposes.

There are many methods to lift downturned corners of the mouth [3]. As minimally invasive procedures, neuromodulator and filler injections are commonly used. However, since the ef- fects of these treatments are limited and temporary, they are reserved for selected patients.

Many authors have described surgical methods for corner mouth lifts (CMLs) [4]. However, most surgeons are reluctant to perform these surgical procedures due to fears of postoperative scarring, especially in Asian patients. In this article, we introduce a new CML technique to reduce postoperative scarring and report our results.

\section{IDEA}

\section{Preoperative planning}

Preoperative planning was performed with the patient in the supine position. After marking the corner of the mouth (point A), a line was drawn along the vermilion-cutaneous border of the upper lip (line a). Point $\mathrm{B}$ was defined as the position of the corner of the mouth desired by the patient. Point $C$ lay within the vermilion-cutaneous border of the upper lip, approximately 13 
mm apart from point $A$, and its location was differentiated by the amount of elevation of the corner of the mouth. A line extending from point $A$ to point $B$ (line $b$ ) and a concave line connecting point $\mathrm{B}$ and point $\mathrm{C}$ (line $\mathrm{c}$ ) were drawn. Point $\mathrm{D}$ was marked on the line where the upper and lower lips met each other and moved into the oral vestibule. Finally, line $d$ was drawn from point $A$ to point $D$. The distance from point $A$ to $D$ was usually half of the distance from point A to point B (Fig. 1).

\section{Surgical methods}

From November 2016 to June 2019, a total of 873 patients underwent a surgical CML at our institution. Of these, we included 312 patients in this study who desired an upturned corner of the mouth with a minimal postoperative scar, for which reason we used the modified CML technique. We performed CML surgery even in young Asian women under 40 years of age, who are susceptible to postoperative scars. We excluded patients with a significant marionette fold and a wide mouth, which was arbitrarily defined as the corners of the mouth being situated laterally of a vertical line from the medial limbus. There were $291 \mathrm{fe}-$ male and 21 male patients, with mean ages of 30 years (range, 18-64 years) and 35 years (range, 22-69 years), respectively. Primary surgery was performed in 273 patients (87.5\%), while 39 patients $(12.5 \%)$ received secondary procedures. CML surgery alone was performed in 112 patients (35.9\%), and the remaining 200 patients (64.1\%) underwent CML surgery concomitantly with other lip and perioral surgical procedures, such as subnasal lift, tubercle correction of the upper lip, lip augmentation, lip reduction, and philtral surgery (Table 1). Informed consent was obtained from each patient. This study was ap- proved by the bioethics committee of our institution under the institutional review board protocol (IRB No. EMCS 2020-06014). All operations were performed under intravenous sedation or local anesthesia. The surgical site was injected with a $2 \%$ lidocaine solution mixed with 1:100,000 epinephrine. After 10 minutes, an incision was made along the drawn incision lines (line a, b, c, and d) with a No. 15 blade. The triangle created by connecting points A, B, and C (Fig. 1) was excised in the subcutaneous plane. A vermilion flap between lines a and $\mathrm{d}$ was dissected in the intramuscular plane of the orbicularis oris muscle until point $A$ could be easily moved to point $B$ without tension. For the release of the marionette fold, the corner of the mouth

\begin{tabular}{|c|c|}
\hline Variable & Value \\
\hline \multicolumn{2}{|l|}{ Sex } \\
\hline Male & $21(6.7)$ \\
\hline Female & $291(93.3)$ \\
\hline \multicolumn{2}{|l|}{ Age (yr) } \\
\hline Male & $30(18-64)$ \\
\hline Female & $35(22-69)$ \\
\hline \multicolumn{2}{|l|}{ Surgery number } \\
\hline Primary & $273(87.5)$ \\
\hline Secondary & 39 (12.5) \\
\hline \multicolumn{2}{|l|}{ Combined surgery } \\
\hline Subnasal lift & $128(41.0)$ \\
\hline Tubercle correction of the upper lip & $77(24.7)$ \\
\hline Lip augmentation & $34(10.9)$ \\
\hline Lip reduction & $19(6.1)$ \\
\hline Philtral surgerya) & $26(8.3)$ \\
\hline
\end{tabular}

\section{Fig. 1. Preoperative planning}

Preoperative design with (A) closed mouth and (B) opened mouth. Point A represents the existing corner of the mouth, and point B represents the position of the corner of the mouth desired by the patient. Point $C$ lies within the vermilion-cutaneous border, approximately $13 \mathrm{~mm}$ apart from point $A$. Point $D$ is marked on the line where the upper and lower lips meet each other and move into the oral vestibule. The lines that connect the points are drawn. Line a connects points $A$ and $C$, and line $b$ connects point $A$ and $B$. Line $c$ represents a concave line connecting points $B$ and C. Finally, line $d$ extends from point $A$ to point $D$. The length of line $d$ is usually half that of line $b$.
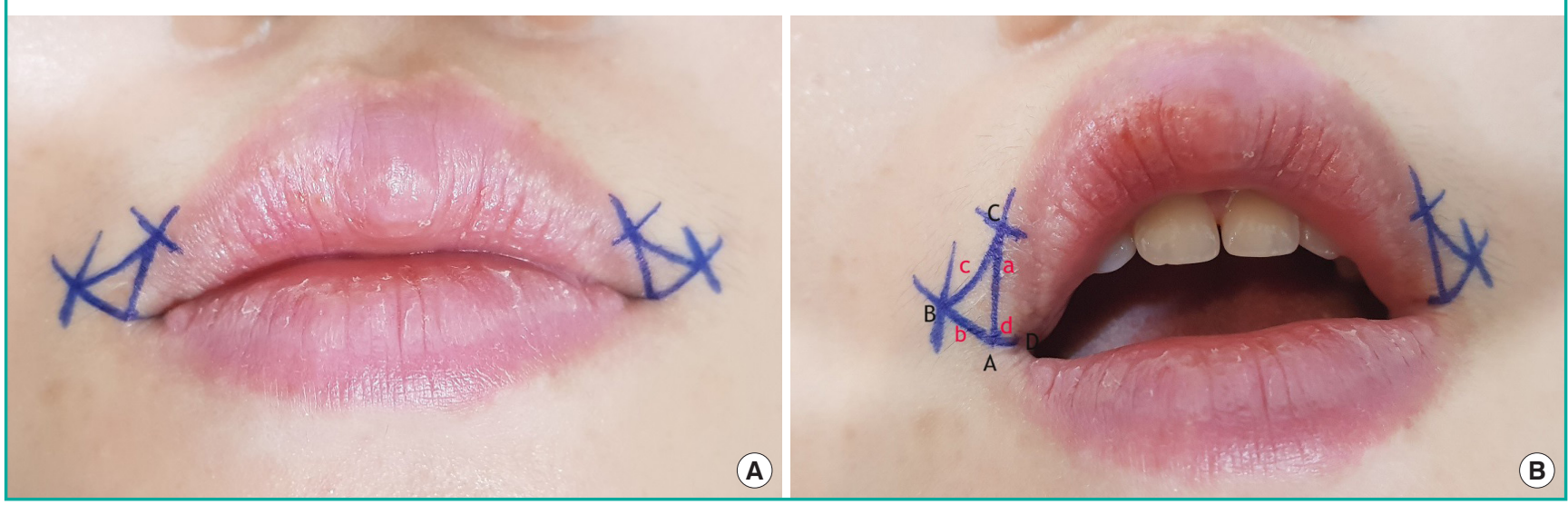


\section{Fig. 2. Case}

A 34-year-old Asian woman who had undergone a corner mouth lift previously with botulinum toxin type $A$ and hyaluronic acid filler. She wanted the corner to be lifted even more and underwent a triangle incision with commissural extension. (A, B) Preoperative view. $(C, D)$ Postoperative view at 5 months after surgery.
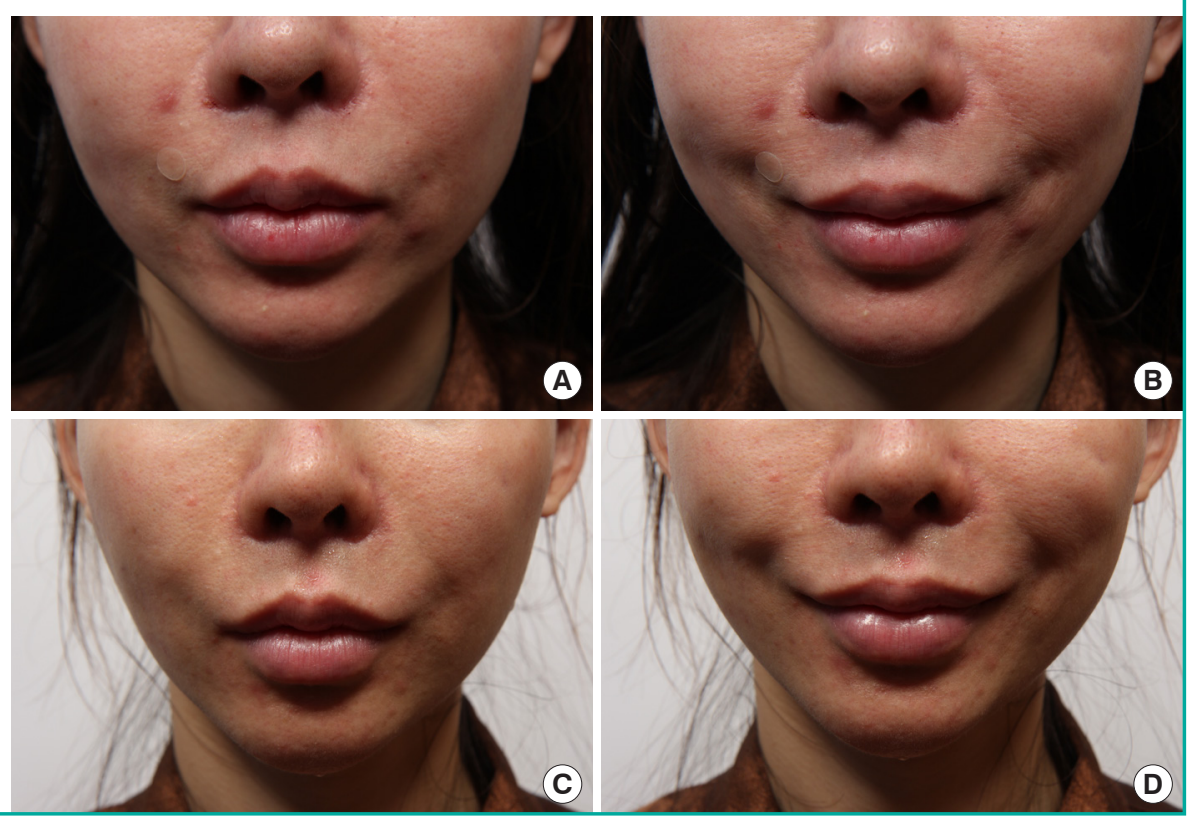

was subcutaneously undermined. The key suture connecting points $A$ and $B$ was performed with a 6-0 monofilament absorbable suture. After confirming that this key suture held firmly, interrupted subcutaneous sutures followed. After treating the dogear that regularly formed at the position of the original mouth corner, the skin suture was carried out using a 7-0 nonabsorbable percutaneous suture (Supplemental Video 1). We applied Steri-Strips (3M Health Care, Saint Paul, MN, USA) across the incision lines to release any tension in the surgical wound. Stitches were removed on postoperative day 5, but Steri-Strips were applied for 2 weeks postoperatively. Most patients were satisfied with the results (Fig. 2).

\section{DISCUSSION}

We introduced a new CML technique to reduce postoperative scarring and reported our results. A considerable amount of research has been performed on aging lips, and lip surgery has mainly been conducted as an ancillary procedure in facial rejuvenation [5]. A traditional facelift may improve jowl and marionette lines to a certain extent. However, traditional facelift procedures are ineffective in alleviating downturned corners of the mouth [6]. Therefore, a direct approach to correct downturned corners of the mouth is necessary, and many surgical methods have been presented to this end [7-9]. Most of these techniques developed for age-related changes cannot be used in young women seeking CML surgery for purely esthetic purposes.

Over the last 8 years, we have evaluated and performed various methods of CML to meet the demands of young patients. Re- cently, we have used only two methods for CML: one is a diamond-shaped incision with a depressor anguli oris muscle release [9], whereas the other method, described in this article, is the triangle incision with commissural extension of the incision.

The diamond-shaped incision can lift the corner of the mouth without detriment to the commissure of the mouth and concomitantly treat the marionette line. However, as the incision extends beyond the mouth corner, it inevitably results in a scar emerging from the vermilion border. The resultant scars are accepted by most patients because these scars fade within the first 6 months postoperatively. However, some patients may develop severe hypertrophic scars, resulting in dissatisfaction with the results. Postoperative scarring has remained one of the major problems to be solved in CML techniques.

Consequently, we conceived a new technique. The underlying concept of what we describe here is that scar problems can be reduced if the CML is performed as a rotation flap using an extended incision through the oral commissure. The resultant scar is situated in the vermilion border and commissure, resulting in a considerably minimized visible scar. Furthermore, as this method involves an incision of the oral commissure, the upper and lower lips are separated, and upper lip movement does not affect lower lip movement, which should reduce the tension in the suture line. We believe that this technique also favorably distributes the direction of scar formation during wound healing. This method leaves a scar along the vermilion border, but the size of this scar is acceptable to most patients. Additionally, Steri-Strips and laser treatment may be used to further reduce the postoperative scar and the risk of hypertrophic scar forma- 
tion $[10,11]$.

We believe that this method could achieve satisfactory results, especially in young Asian women, who are particularly susceptible to scars.

\section{NOTES}

\section{Conflict of interest}

No potential conflict of interest relevant to this article was reported.

\section{Ethical approval}

The study was approved by the Institutional Review Board of Eulji Medical Center (IRB No. EMCS 2020-06-014) and performed in accordance with the principles of the Declaration of Helsinki. Written informed consent was obtained.

\section{Patient consent}

The patient provided written informed consent for the publication and the use of her images.

\section{Author contribution}

Conceptualization: HJ Lee, TK Jeong. Data curation: HJ Lee, $\mathrm{KH}$ Min, CH Jeong, TK Jeong. Formal analysis: HJ Lee, $\mathrm{KH}$ Min, JH Jeong, TK Jeong. Methodology: HJ Lee, TK Jeong. Project administration: HJ Lee, KH Min, TK Jeong. Visualization: HJ Lee, TK Jeong. Writing-original draft: KH Min, HJ Lee, CH Jeong, TK Jeong. Writing-review \& editing: KH Min, HJ Lee, CH Jeong, TKJeong.

\section{ORCID}

Kyung Hee Min https://orcid.org/0000-0002-3456-0191

Hyun Jic Lee Chnag Ho Jeong https://orcid.org/0000-0003-1479-5740

Tae Kwang Jeong https://orcid.org/0000-0002-9431-737X https://orcid.org/0000-0003-0285-2410

\section{Supplementary material}

Supplemental Video 1. Surgical methods. Supplemental data can be found at: https://doi.org/10.5999/aps.2020.00444.v001.

\section{REFERENCES}

1. Ellis DAF, Bakala CD, Harlock JN. Analysis of the peri-oral complex. Facial Plast Surg Clin North Am 1997;5:1-6.

2. Spiegel JH, Spiegel OL. Lip lifting: not just fullness-everything you need to know about lifting and creating youthful, beautiful lips. Facial Plast Surg 2019;35:129-33.

3. Austin HW, Weston GW. Rejuvenation of the aging mouth. Clin Plast Surg 1992;19:511-24.

4. Cheng JT, Perkins SW, Hamilton MM. Perioral rejuvenation. Facial Plast Surg Clin North Am 2000;8:223-33.

5. Chang CS, Chang BL, Lanni M, et al. Perioral rejuvenation: a prospective, quantitative dynamic three-dimensional analysis of a dual modality treatment. Aesthet Surg J 2018;38:122536.

6. Ramirez OM. Three-dimensional endoscopic midface enhancement: a personal quest for the ideal cheek rejuvenation. Plast Reconstr Surg 2002;109:329-40.

7. Parsa FD, Parsa NN, Murariu D. Surgical correction of the frowning mouth. Plast Reconstr Surg 2010;125:667-76.

8. Weston GW, Poindexter BD, Sigal RK, et al. Lifting lips: 28 years of experience using the direct excision approach to rejuvenating the aging mouth. Aesthet Surg J 2009;29:83-6.

9. Jeong TK. Surgical method of a corner mouth lift. Plast Reconstr Surg Glob Open 2020;8:e2653.

10. Reiffel RS. Prevention of hypertrophic scars by long-term paper tape application. Plast Reconstr Surg 1995;96:17158.

11. Atkinson JA, McKenna KT, Barnett AG, et al. A randomized, controlled trial to determine the efficacy of paper tape in preventing hypertrophic scar formation in surgical incisions that traverse Langer's skin tension lines. Plast Reconstr Surg 2005;116:1648-56. 